\title{
Correlation of Histopathology With Anorectal Manometry Following Stapled Hemorrhoidopexy
}

\author{
Young Ki Hong, Yoon Jung Choi ${ }^{1}$, Jung Gu Kang \\ Departments of Surgery and ${ }^{1}$ Pathology, National Health Insurance Corporation Ilsan Hospital, Goyang, Korea
}

Purpose: The removal of smooth muscle during stapled hemorrhoidopexy raises concerns regarding its effects on postoperative anorectal function. The purpose of this study was to evaluate the correlation between the amount of muscle removed and changes in anorectal manometry following stapled hemorrhoidopexy.

Methods: Patients with symptomatic II, III, or IV degree hemorrhoids that underwent stapled hemorrhoidopexy between January 2008 and May 2011 were included in this study. Anorectal manometry was performed preoperatively and at three months postoperatively. The resected doughnuts were examined histologically, and the thicknesses of muscle fibers were evaluated.

Results: Eighty-five patients ( 34 males) with a median age of 47 years were included. Muscularis propria fibers were identified in 63 of 85 pathologic specimens (74.1\%). The median thickness of the muscle fibers was $1.58 \pm 1.21 \mathrm{~mm}(0$ to 4.5 $\mathrm{mm})$. The mean resting pressure decreased by approximately $7 \mathrm{mmHg}$ after operation in the 85 patients $(\mathrm{P}=0.019)$. In patients with muscle incorporation, there was a significant difference in mean resting pressure $(\mathrm{P}=0.041)$. In the analysis of the correlation of the difference in anorectal manometry results ([the result of postsurgical anorectal manometry] - [the result of presurgical anorectal manometry]) to the thickness of muscle fibers, no significant differences were seen. No patients presented with fecal incontinence.

Conclusion: Although the incidence of fecal incontinence is very low, muscle incorporation in the resected doughnuts following stapled hemorrhoidopexy may affect anorectal pressure. Therefore, surgeons should endeavor to minimize internal sphincter injury during stapled hemorrhoidopexy.

Keywords: Hemorrhoids; Manometry; Muscle; Incontinence

\section{INTRODUCTION}

The stapled hemorrhoidopexy was first introduced by Longo [1] in 1998. The procedure has since been performed more commonly and has gradually become a widespread alternative to the conventional hemorrhoidectomy. Unlike in the hemorrhoidec-

Received: April 13, 2013 - Accepted: May 14, 2013

Correspondence to: Jung Gu Kang, M.D.

Department of Surgery, National Health Insurance Corporation Ilsan

Hospital, 100 Ilsan-ro, Ilsandong-gu, Goyang 410-719, Korea

Tel: +82-31-900-0216, Fax: +82-31-900-0343

E-mail:kangski@nhimc.or.kr

(C) 2013 The Korean Society of Coloproctology

This is an open-access article distributed under the terms of the Creative Commons Attribution NonCommercial License (http://creativecommons.org/licenses/by-nc/3.0) which permits unrestricted non-

commercial use, distribution, and reproduction in any medium, provided the original work is properly cited. tomy, in the stapled hemorrhoidopexy, the anastomosis area is placed above the dentate line to avoid areas that can present with severe pain and wounds are not generated in the external anus. Therefore, the stapled hemorrhoidopexy is associated with less postoperative pain, reduced operative time, and superior patient satisfaction rates when compared with the traditional method [24]. The principle of this technique involves interruption of the blood flow to the hemorrhoids by circumferentially excising the mucosa and submucosa rather than the hemorrhoids themselves. The hemorrhoids are not excised, but are reduced and fixed to the staple line in the anal canal, the more normal physiological site. Therefore, the original description of the technique emphasized that the sphincter muscle should not be included in the pursestring suture performed during the surgery [1-5]. However, several previous reports have indicated the inclusion of muscle fibers in the resected tissues after a stapled hemorrhoidopexy; thus, con- 
cerns have been raised about the effect of resected muscles on postoperative anorectal function [6-9]. Therefore, we examined the effect of this technique on anorectal function by correlating the thickness of muscle fibers included in excised doughnuts after a stapled hemorrhoidopexy with changes in anorectal manometry from prior to surgery to after surgery.

\section{METHODS}

This retrospective study was conducted in a sample of 85 patients with symptomatic II, III, or IV degree hemorrhoids who underwent a stapled hemorrhoidopexy at the Department of Surgery, National Health Insurance Corporation Ilsan Hospital, from January 2008 to May 2011. The proximate HCS hemorrhoidal circular stapler PPH 03 (Procedure for Prolapse and Hemorrhoids, 33$\mathrm{mm}$ circular stapling device, Ethicon Endo-Surgery, Cincinnati, $\mathrm{OH}, \mathrm{USA}$ ) kit was used for all procedures. Considering the mobility and the size of hemorrhoid tissues, we performed a pursestring suture with 2-0 Prolene in the area 3 to $4 \mathrm{~cm}$ above the dentate line. Before firing the stapler, we performed a digital vaginal examination in female patients to ensure that the posterior vaginal wall had not been incorporated in the suture. After firing the stapler, we performed hemostasis by using electrocauterization, and we used 4-0 Vicryl absorbable sutures over-sew any bleeding points on the stapled line. External components that remained even after the stapler had been fired were removed by electrocoagulation or ligasure, if necessary. The resected doughnuts were spread without folding, immobilized on tongue depressors, and sent to the Department of Pathology. After fixation in $10 \%$ formalin, the specimens were sectioned and stained with hematoxylin and eosin. Three to five slides were made for each specimen, and the maximum thickness of muscle fiber was measured by pathologists using the Image-Pro Plus 6.2 (Media Cybernetics Inc., Silver Spring, MD, USA) (Fig. 1).

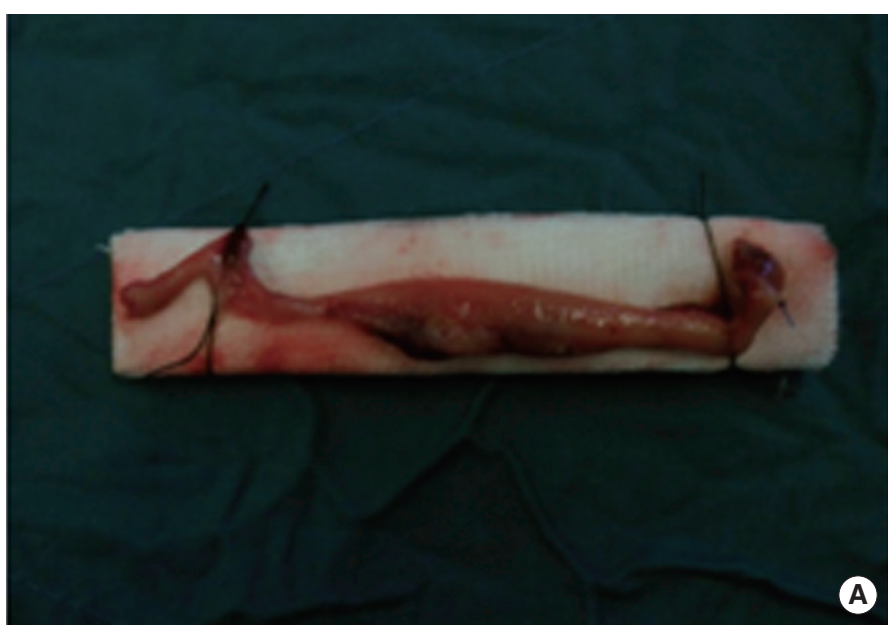

Anorectal manometry was performed prior to surgery and 3 months after surgery by a single technician. The rectum was cleaned with a bisacodyl rectal suppository at least 2 hours before the test. The patient was placed in the left lateral decubitus position with knees flexed. For anal manometry, a Polygraf ID (Medtronic Functional Diagnostics A/S system, Skovlunde, Denmark) was used. Manometric evaluation was carried out using an eight-channel catheter with a radial arrangement of channel apertures. After calibration, a continuously perfused catheter was introduced into the rectal ampulla up to $6 \mathrm{~cm}$ from the anal verge, and after the pressure had been set by using a continuous pull-through method, a mechanical puller device, at a constant speed of $1 \mathrm{~cm}$ per second, was pulled through the sphincter (rapid pull-through test). Resting and squeezing pressures were calculated twice. The maximal resting pressure, the maximal squeezing pressure, the mean resting pressure, the mean squeezing pressure, and the length of the high pressure zone were measured, and the values prior to surgery were compared with the values after surgery. Additionally, we analyzed the correlation between the changes in anorectal manometry results and the maximal thickness of the muscle fiber included in the resected doughnuts.

Concerning postsurgical pain, from immediately after surgery to 7 days after surgery, the pain score was assessed according to a visual analog scale. Without pain was 0 points, and the state with maximal pain was 10 points. The scores were recorded by the patients themselves by marking the scale directly. Postsurgical complications were assessed by referring to the medical record of outpatient clinics and by telephone interviews.

The SPSS ver. 15.0 (SPSS Inc., Chicago, IL, USA) was used for statistical analyses. The Wilcoxon test was applied for changes in anorectal manometry results. For analysis of the correlation between the differences in anorectal manometry results and the thickness of muscle tissues, a bivariate correlation analysis was applied. Discrete variables are presented as medians (minimum-

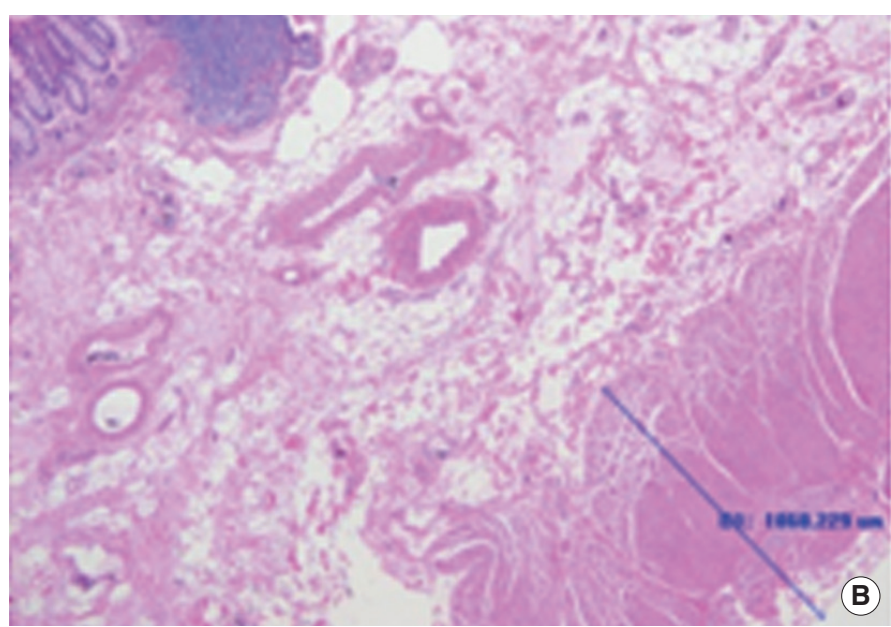

Fig. 1. Histopathologic examination for measurement of muscle thickness. (A) Specimen was sent to pathology without folding. (B) The thickness of muscle fibers obtained using Image-Pro Plus 6.2 (Media Cybernetics Inc.) $(\mathrm{H} \& \mathrm{E}, \times 40)$. 
maximum). Continuous variables are presented as a mean \pm standard deviation. P-values of less than 0.05 were considered statistically significant.

\section{RESULTS}

\section{General characteristics}

The median age of the patients was 47 years (21 to 72 years). The ratio of males to females was $34: 51(1: 1.5)$. Regarding indications for surgery, 34 cases (40\%) had II degree, 49 cases (57.6\%) had III degree, and 2 cases (2.3\%) had IV degree hemorrhoids. No patients had undergone prior anorectal operations.

\section{Operation records}

Regarding anesthesia, spinal anesthesia was used in 81 cases (95.3\%) and general anesthesia in 4 cases. The median operative time was 20 minutes (10 to 45 minutes). In 75 patients (88.2\%), external components (median, 2; range, 0 to 5) were resected after firing the stapler. In regard to the postsurgical hospitalization period, discharge on the day of surgery occurred in 1 case (1.2\%), hospitalization for 1 day occurred in 64 cases (75.3\%), hospitalization for 2 days occurred in 18 cases (2.4\%), and hospitalization for 4 days and 6 days occurred in 1 case each (1.2\%).

\section{Histopathological results}

Sixty-three patients had muscle tissue in the resected doughnuts

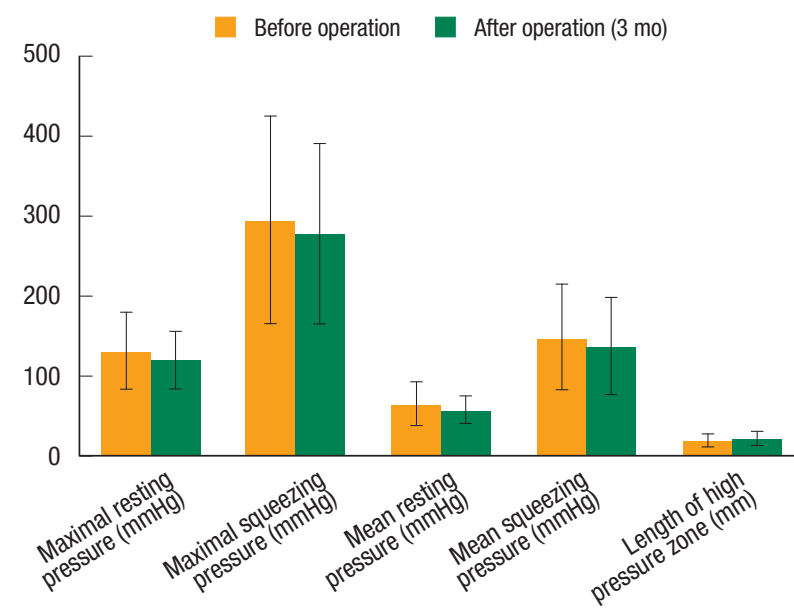

\begin{tabular}{lccccc}
\hline & $\begin{array}{c}\text { Maximal RP } \\
(\mathrm{mmHg})\end{array}$ & $\begin{array}{c}\text { Maximal SP } \\
(\mathrm{mmHg})\end{array}$ & $\begin{array}{c}\text { Mean RP } \\
(\mathrm{mmHg})\end{array}$ & $\begin{array}{c}\text { Mean SP } \\
(\mathrm{mmHg})\end{array}$ & $\begin{array}{c}\mathrm{HPZ} \\
(\mathrm{mm})\end{array}$ \\
\hline Before operation & $132.7 \pm 49.0$ & $294.9 \pm 127.5$ & $65.6 \pm 26.2$ & $149.3 \pm 65.5$ & $20.8 \pm 7.1$ \\
After operation & $120.6 \pm 35.9$ & $277.8 \pm 111.2$ & $58.4 \pm 17.9$ & $138.0 \pm 60.1$ & $22.7 \pm 8.0$ \\
P-value & 0.072 & 0.296 & 0.019 & 0.051 & 0.073 \\
\hline
\end{tabular}

Fig. 2. Change in anorectal manometry $(\mathrm{n}=85)$. Values are presented as mean \pm standard deviation. $\mathrm{RP}$, resting pressure; SP, squeezing pressure; HPZ, high pressure zone.
(74.1\%), and the maximum thickness of muscle fibers were $1.58 \pm$ $1.21 \mathrm{~mm}$ (0 to $4.5 \mathrm{~mm})$. In the 63 cases where muscle fiber was detected, in 62 cases (98.4\%), only smooth muscle was detected, and a striated muscle, together with a smooth muscle, was seen in one case.

\section{Change of anorectal manometry results from before operation to after operation}

For the 85 patients, in the anorectal manometry performed before operation, the maximal resting pressure was $132.7 \pm 49.0 \mathrm{mmHg}$, the maximal squeezing pressure was $294.9 \pm 127.5 \mathrm{mmHg}$, the mean resting pressure was $65.6 \pm 26.2 \mathrm{mmHg}$, the mean squeezing pressure was $149.3 \pm 65.5 \mathrm{mmHg}$, and the length of the high pressure zone was $20.8 \pm 7.1 \mathrm{~mm}$. Except for the mean resting pressure, the results of anorectal manometry were not significantly different before and after surgery. The mean resting pressure was decreased by approximately $7 \mathrm{mmHg}$ after operation $(\mathrm{P}=0.019)$ (Fig. 2).

Similar analyses of the 22 patients without muscle incorporation (Fig. 3) and the 63 patients with muscle incorporation (Fig. 4) demonstrated no significant differences in anorectal manometry before or after operation. In patients with muscle incorporation, however, there were significant differences in the mean resting pressure $(P=0.041)$, mean squeezing pressure $(P=0.036)$, and length of the high pressure zone $(\mathrm{P}=0.016)$. In a comparison of the anorectal manometry results ([the result of postsurgical ano-

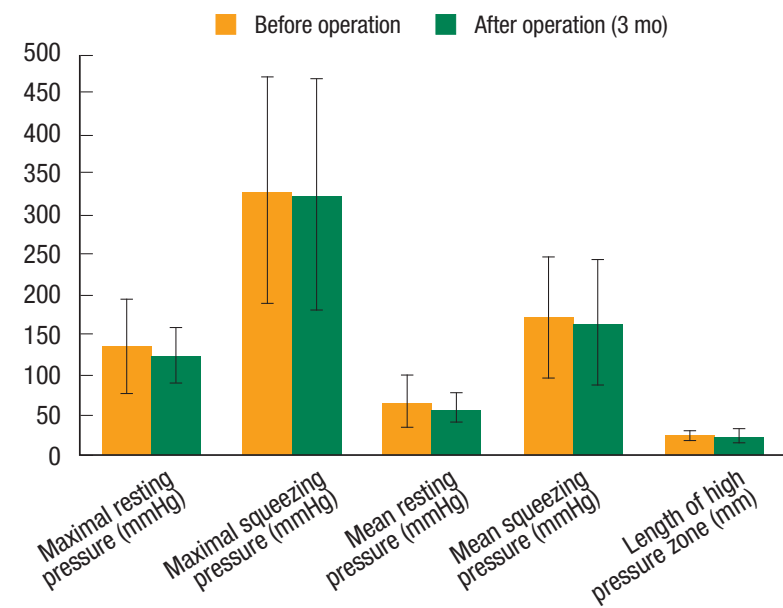

\begin{tabular}{lccccc}
\hline & $\begin{array}{c}\text { Maximal RP } \\
(\mathrm{mmHg})\end{array}$ & $\begin{array}{c}\text { Maximal SP } \\
(\mathrm{mmHg})\end{array}$ & $\begin{array}{c}\text { Mean RP } \\
(\mathrm{mmHg})\end{array}$ & $\begin{array}{c}\text { Mean SP } \\
(\mathrm{mmHg})\end{array}$ & $\begin{array}{c}\mathrm{HPZ} \\
(\mathrm{mm})\end{array}$ \\
\hline Before operation & $134.6 \pm 57.9$ & $329.0 \pm 141.8$ & $66.1 \pm 33.1$ & $171.3 \pm 76.2$ & $24.2 \pm 6.9$ \\
After operation & $122.8 \pm 35.2$ & $324.0 \pm 144.0$ & $57.7 \pm 17.5$ & $164.5 \pm 79.2$ & $23.3 \pm 9.6$ \\
P-value & 0.592 & 0.884 & 0.205 & 0.808 & 0.626 \\
\hline
\end{tabular}

Fig. 3. Change in anorectal manometry in patients without muscle incorporation $(n=22)$. Values are presented as mean \pm standard deviation. RP, resting pressure; SP, squeezing pressure; $\mathrm{HPZ}$, high pressure zone. 


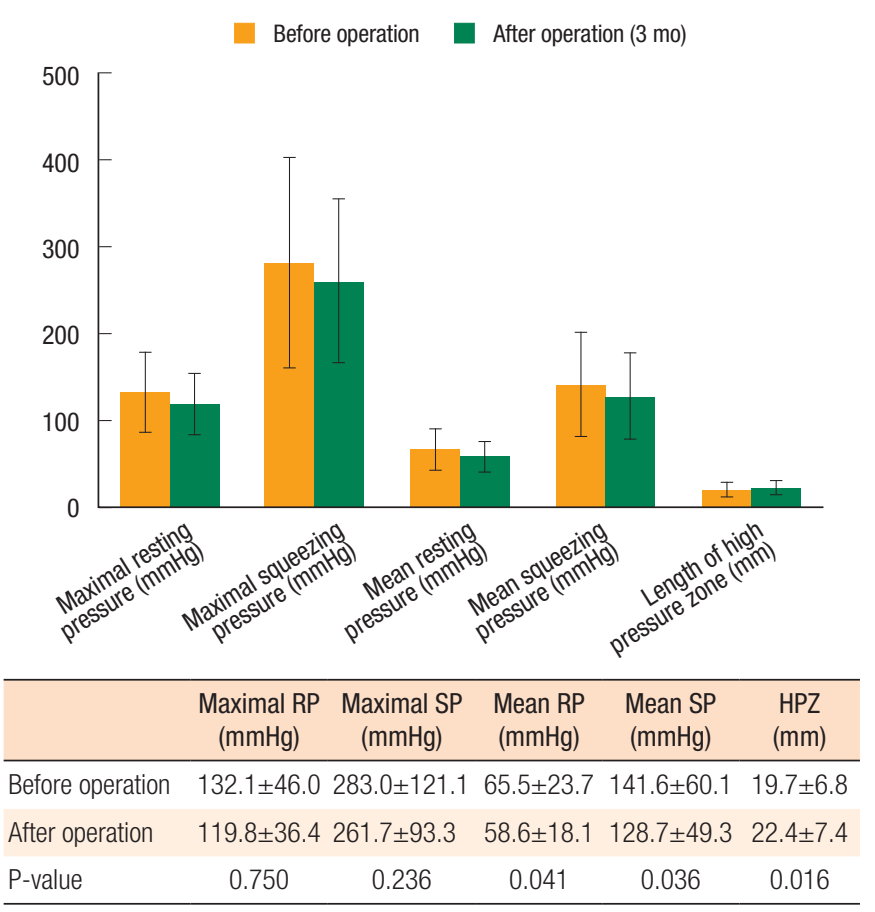

Fig. 4. Change in anorectal manometry for patients whose specimen had muscle involvement $(n=63)$. Values are presented as mean \pm standard deviation. RP, resting pressure; SP, squeezing pressure; HPZ, high pressure zone.

rectal manometry] - [the result of presurgical anorectal manometry]) to the maximum thickness of the muscle fiber, no significant differences were seen (Fig. 5).

\section{Postoperative outcomes}

Patients presented with headache in 2 cases (2.4\%), anal bleeding in 3 cases (3.6\%), and frequent defecation in 1 case (1.2\%). No patients presented with anal stricture or fecal incontinence (Table 1). Anal bleeding was controlled with conservative management, and no patients required admission or repeat surgery. On postoperative day 7,6 patients $(7.1 \%)$ presented with pain higher than 3 points on the visual analog scale. In these 6 patients, the maximum thickness of the muscle fiber contained in the resected doughnuts was $1.9 \pm 1.16 \mathrm{~mm}$ (0 to $3.6 \mathrm{~mm})$.

\section{DISCUSSION}

Since Longo [1] introduced the stapled hemorrhoidopexy in 1998, numerous studies using this technique have been reported; outcomes from our hospital were previously reported in 2001 [10]. Randomized control trials have demonstrated that the stapled hemorrhoidopexy is associated with less postoperative pain, reduced operative time, and superior patient satisfaction rates compared with the traditional method because the surgical anastomosis area is located above the dentate line and does not leave a peri-
Table 1. Follow-up and complications $(\mathrm{n}=85)$

\begin{tabular}{ll}
\hline Complication & Value \\
\hline Anal bleeding & $3(3.6)$ \\
Headache & $2(2.4)$ \\
Defecation frequency & $1(1.2)$ \\
Anal stenosis & $0(0)$ \\
Fecal incontinence & $0(0)$ \\
Total & $6(7.2)$ \\
\hline
\end{tabular}

Values are presented as no. of cases (\%).

anal wound $[2,3]$. Nevertheless, several investigators have voiced concern over the removal of muscle fibers during the stapled hemorrhoidopexy and its possible effects on postoperative anorectal function [7, 9, 11-15]. Cheetham et al. [15] stated that resected smooth muscles may play an important role in persistent postoperative pain and fecal urgency. Beattie and Loudon [16] reported that smooth muscle incorporation in the resected doughnuts was inevitable, but that it had no effect on the postoperative pain score or symptoms in patients with resected smooth muscle. Kam et al. [7] reported that the mean resting pressure of patients was reduced by $11 \mathrm{mmHg}$ after a stapled hemorrhoidopexy; nonetheless, the amount of resected muscle did not correlate with the reduction in the mean resting pressure. Sileri et al. [11] suggested the possibility that resected muscle fibers might be associated with postsurgical hemorrhage, although they did not correlate it with anorectal function. In addition, Fazio [17] emphasized the importance of the location of the purse-string suture, as injury of the internal sphincter might be a cause of sphincter dysfunction if the purse-string suture were to be too close to the dentate line.

We identified muscle fibers in the specimens of 63 patients (74.1\%). In previous studies, the presence of muscle fibers in the resected doughnuts has been reported to occur in between $4 \%$ and $97 \%$ of the cases [6]. Nevertheless, previous studies have reported that the presence of resected muscle fibers does not affect the fecal incontinence score or postoperative pain $[7,8,11]$. The incidence of fecal incontinence developing after a stapled hemorrhoidopexy is generally reported to be less than $1 \%[9,18,19]$. Naldini et al. [6] identified muscularis propria in the specimens of $90 \%$ of 241 patients. Between a group with muscle fibers in the resected specimen and a group without resected muscle, postoperative fecal incontinence and anal pain were not significantly different. Rather, in the no resected muscle group, the complication rate was higher than it was in the resected muscle group. In other words, they stated that it was not rare to resect muscle fibers during a stapled hemorrhoidopexy, though this might not affect the postsurgical outcomes of patients.

Previous studies have assessed whether muscle fibers were included in resected specimens and the resultant effects on anorectal function and complications. In the current study, we attempted to analyze the correlation between the amount of resected muscle 

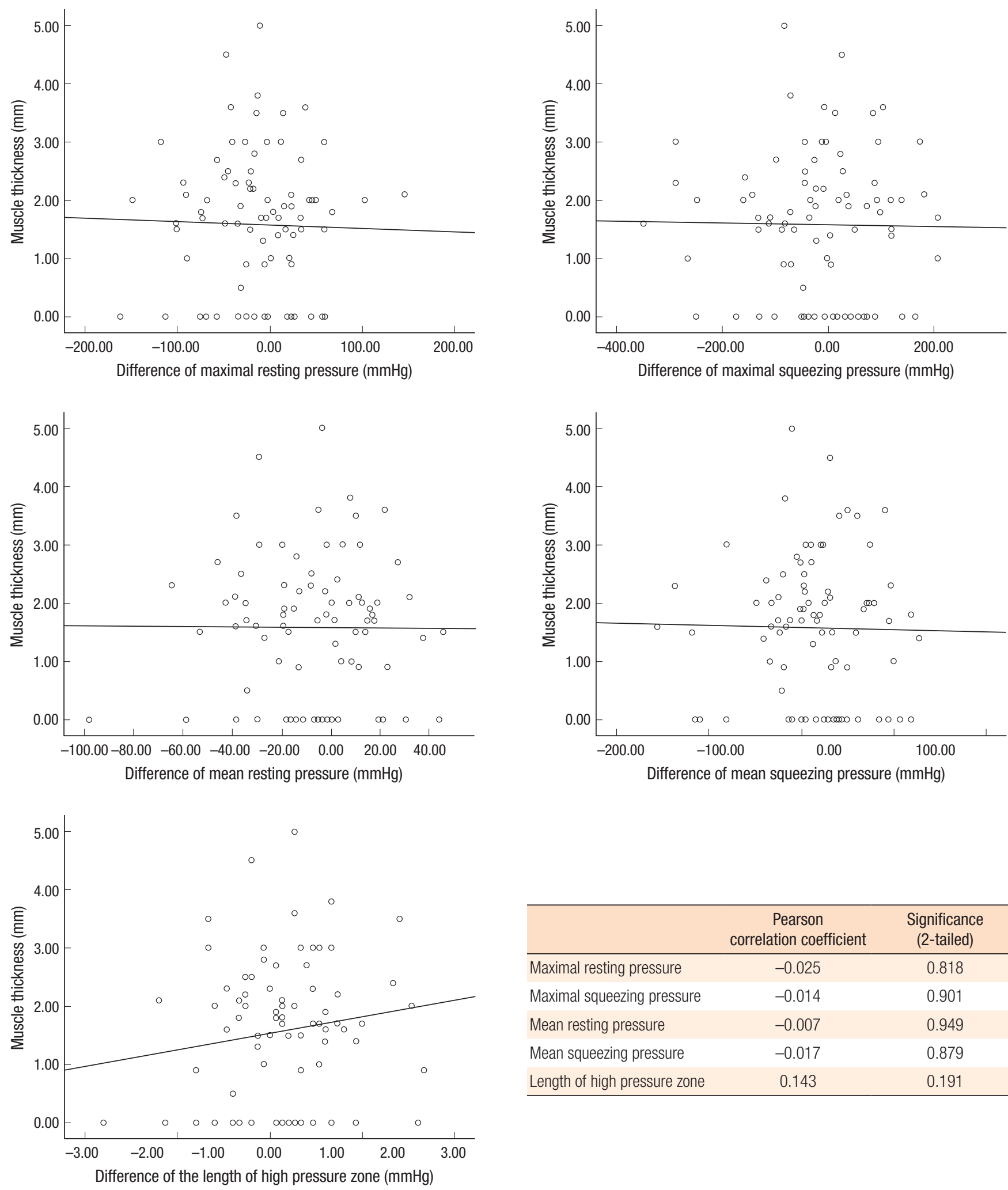

\begin{tabular}{lcc}
\hline & $\begin{array}{c}\text { Pearson } \\
\text { correlation coefficient }\end{array}$ & $\begin{array}{c}\text { Significance } \\
\text { (2-tailed) }\end{array}$ \\
\hline Maximal resting pressure & -0.025 & 0.818 \\
Maximal squeezing pressure & -0.014 & 0.901 \\
Mean resting pressure & -0.007 & 0.949 \\
Mean squeezing pressure & -0.017 & 0.879 \\
Length of high pressure zone & 0.143 & 0.191 \\
\hline
\end{tabular}

Fig. 5. Correlation between muscle thickness and postoperative change in anorectal manometry (postoperative anorectal manometry - preoperative anorectal manometry) $(n=85)$. 
fibers and the effects on anorectal function by measuring the amount of resected muscle tissues in pathological specimens. A measurement of the volume of muscle fibers is more accurate for assessing the amount of resected muscle fibers, but this is technically difficult. Thus, the thickness of muscle fiber was measured precisely, and the correlation of the thickness of muscles to the result of anorectal manometry was assessed. In the present study, we observed a decreased mean resting pressure of approximately $7 \mathrm{mmHg}$ after a stapled hemorrhoidopexy $(\mathrm{P}=0.019)$. In addition, the mean resting pressure $(\mathrm{P}=0.041)$, mean squeezing pressure $(\mathrm{P}=0.036)$ and length of the high pressure zone $(\mathrm{P}=0.016)$ were significantly altered after a stapled hemorrhoidopexy in patients with muscle incorporation. These results suggest that a stapled hemorrhoidopexy can affect anorectal pressure, especially in patients with muscle incorporation. Fecal incontinence, however, did not develop in any patient in the current study. As reported in previous studies, fecal incontinence after a stapled hemorrhoidopexy is very rare; the possibility that altered anorectal pressure can lead to fecal incontinence is very low. Even if the sphincter is not incorporated into the resected doughnuts, the internal sphincter can be damaged when it is stretched by the stapler head or by the anoscope. That the anoscope can damage the sphincter was shown in a study using a stapled ileopouch anal anastomosis model [20, 21]. Also, in our 22 patients without muscle incorporation, the resting and the squeezing pressures were decreased after a stapled hemorrhoidopexy, although this decrease was not statistically significant. In the current study, the mean squeezing pressure was altered significantly after a stapled hemorrhoidopexy in patients with muscle incorporation. The mean squeezing pressure mainly reflects the external sphincter function. Although striated muscle was found in the specimen of one patient, this was an unexpected result. One could suppose that the staple might affect the external sphincter pressure, but further investigation is needed.

Thaha et al. [22] reported 3 patients with persistent postdefecation pain among 77 patients following a stapled hemorrhoidopexy. Of these three patients, a large amount of muscle incorporation was observed in the specimens of two patients. However, there were no sphincter defects on endorectal ultrasonography; thus, the authors supposed that the cause of the postdefecation pain might have been damage to the neural plexus located in rectal subcutaneous tissues rather than damage to the sphincter. In the current study, six patients presented with anal pain one week after surgery, but the pain was resolved within two weeks. The maximum thickness of muscle fiber contained in their resected doughnuts was $1.9 \pm 1.16 \mathrm{~mm}$ (0 to $3.6 \mathrm{~mm}$ ), which was not significantly different from the average. On the other hand, external components are resected after stapled hemorrhoidopexy in our hospital, if required, and this may have caused the resultant pain. The limitation of a small number of subject patients should be considered. In one patient, resected tissues contained not only smooth muscle but also striated muscle. The maximum thickness of muscle fiber in this patient was $3.6 \mathrm{~mm}$, and one external com- ponent was removed. The visual analog pain scale of this patient immediately after surgery was 5 points, and after one week was 3 points. Afterward, the pain was resolved. Due to the limitation of retrospective studies, the cause could not be elucidated. Nonetheless, the possibility that the cause might have been due to the location of the purse-string suture being too low or due to the removal of external components could not be ruled out.

Many authors have emphasized the importance of the location of the stapler line $[2,5,10-14,16,17]$. In our hospital, we endeavor to make a mucosal purse-string suture in an area 3 to $4 \mathrm{~cm}$ above the dentate line and a circular staple line at approximately $2 \mathrm{~cm}$ above the dentate line. Too high a staple line may be associated with early recurrence and a lower staple line may be responsible for greater pain and for higher analgesic requirement. A previous report demonstrated that, in approximately $80 \%$ of the cases, the excised specimens contained not only mucosa and submucosa but, more frequently than expected, also smooth muscle of the internal anal sphincter (38\% of cases) and of the rectum ( $42 \%$ of cases) [23]. Altomare et al. [24] presumed that the smooth muscle fibers in the resected doughnuts belonged to the low rectum, not the internal sphincter. If internal sphincter damage is to be minimized, a staple line at $2 \mathrm{~cm}$ above the dentate line seems to be appropriate, and smooth muscle incorporation of the low rectum, not the internal sphincter, would not mediate a great effect on anorectal function. Additionally, patients with less mucosal redundancy due to scarring of the anoderm from a previous anorectal surgery or radiation do not seem to be be appropriate candidates for a stapled hemorrhoidopexy as scarring of the anoderm is a risk for incorporation of the internal sphincter musculature with the purse-string suture.

Finally, we observed one patient who complained of defecation frequency after a stapled hemorrhoidopexy. Corsetti et al. [25] suggested that rectal distensibility and volume thresholds for sensation were decreased after a stapled hemorrhoidopexy. In the current study, we focused on the anorectal pressure and its correlation with muscle incorporation in resected doughnuts. Thus, we did not calculate the volume thresholds in all patients. However, in this patient, the maximum volume threshold was decreased from $140 \mathrm{~mL}$ before the stapled hemorrhoidectomy to $80 \mathrm{~mL}$ after the stapled hemorrhoidectomy. More investigations will be required to verify the influence of a stapled hemorrhoidectomy on rectal distensibility.

In conclusion, the simple mucosal resection described by Longo is ideal, but it is difficult to avoid resecting muscle fibers when using this technique. Although the incidence of fecal incontinence is very low and the maximum thickness of muscle fibers were not significantly correlated to differences in anorectal manometry, muscle incorporation in the resected doughnuts following a stapled hemorrhoidopexy may mediate effects on the anorectal pressure. Together, these results suggest that surgeons should endeavor to minimize internal sphincter injury during a stapled hemorrhoidopexy. 


\section{CONFLICT OF INTEREST}

No potential conflict of interest relevant to this article was reported.

\section{REFERENCES}

1. Longo A. Treatment of hemorrhoidal disease by reduction of mucosa and haemorrhoidal prolapse with a circular suturing device: a new procedure. In: Proceedings of the Sixth World Congress of Endoscopic Surgery; 1998 Jun 3-6; Rome, Italy; Bologna: Monduzzi Editore; 1998:777-84.

2. Shalaby R, Desoky A. Randomized clinical trial of stapled versus Milligan-Morgan haemorrhoidectomy. Br J Surg 2001;88:1049-53.

3. Ganio E, Altomare DF, Gabrielli F, Milito G, Canuti S. Prospective randomized multicentre trial comparing stapled with open haemorrhoidectomy. Br J Surg 2001;88:669-74.

4. Rowsell M, Bello M, Hemingway DM. Circumferential mucosectomy (stapled haemorrhoidectomy) versus conventional haemorrhoidectomy: randomised controlled trial. Lancet 2000;355:77981.

5. Lloyd D, Ho KS, Seow-Choen F. Modified Longo's hemorrhoidectomy. Dis Colon Rectum 2002;45:416-7.

6. Naldini G, Martellucci J, Moraldi L, Romano N, Rossi M. Is simple mucosal resection really possible? Considerations about histological findings after stapled hemorrhoidopexy. Int J Colorectal Dis 2009;24:537-41.

7. Kam MH, Mathur P, Peng XH, Seow-Choen F, Chew IW, Kumarasinghe MP. Correlation of histology with anorectal function following stapled hemorrhoidectomy. Dis Colon Rectum 2005;48: 1437-41.

8. Esser S, Khubchandani I, Rakhmanine M. Stapled hemorrhoidectomy with local anesthesia can be performed safely and cost-efficiently. Dis Colon Rectum 2004;47:1164-9.

9. Ho YH, Cheong WK, Tsang C, Ho J, Eu KW, Tang CL, et al. Stapled hemorrhoidectomy--cost and effectiveness. Randomized, controlled trial including incontinence scoring, anorectal manometry, and endoanal ultrasound assessments at up to three months. Dis Colon Rectum 2000;43:1666-75.

10. Kang JG, Lee SY, Lee SH. Clinical study of circular stapler hemorrhoidectomy. J Korean Soc Coloproctol 2005;21:370-75.

11. Sileri P, Stolfi VM, Palmieri G, Mele A, Falchetti A, Di Carlo S, et al. Stapled hemorrhoidopexy: a prospective study from pathology to clinical outcome. J Gastrointest Surg 2007;11:1662-8.

12. Ohana G, Myslovaty B, Ariche A, Dreznik Z, Koren R, Rath-Wolf- son L. Mid-term results of stapled hemorrhoidopexy for thirdand fourth-degree hemorrhoids: correlation with the histological features of the resected tissue. World J Surg 2007;31:1336-42.

13. Plocek MD, Kondylis LA, Duhan-Floyd N, Reilly JC, Geisler DP, Kondylis PD. Hemorrhoidopexy staple line height predicts return to work. Dis Colon Rectum 2006;49:1905-9.

14. Correa-Rovelo JM, Tellez O, Obregon L, Duque-Lopez X, Miranda-Gomez A, Pichardo-Bahena R, et al. Prospective study of factors affecting postoperative pain and symptom persistence after stapled rectal mucosectomy for hemorrhoids: a need for preservation of squamous epithelium. Dis Colon Rectum 2003;46:955-62.

15. Cheetham MJ, Mortensen NJ, Nystrom PO, Kamm MA, Phillips RK. Persistent pain and faecal urgency after stapled haemorrhoidectomy. Lancet 2000;356:730-3.

16. Beattie GC, Loudon MA. Pain after stapled haemorrhoidectomy. Lancet 2000;356:2189.

17. Fazio VW. Early promise of stapling technique for haemorrhoidectomy. Lancet 2000;355:768-9.

18. Ravo B, Amato A, Bianco V, Boccasanta P, Bottini C, Carriero A, et al. Complications after stapled hemorrhoidectomy: can they be prevented? Tech Coloproctol 2002;6:83-8.

19. Hetzer FH, Demartines N, Handschin AE, Clavien PA. Stapled vs excision hemorrhoidectomy: long-term results of a prospective randomized trial. Arch Surg 2002;137:337-40.

20. Ho YH, Tan M, Leong A, Eu KW, Nyam D, Seow-Choen F. Anal pressures impaired by stapler insertion during colorectal anastomosis: a randomized, controlled trial. Dis Colon Rectum 1999;42: 89-95.

21. Tuckson W, Lavery I, Fazio V, Oakley J, Church J, Milsom J. Manometric and functional comparison of ileal pouch anal anastomosis with and without anal manipulation. Am J Surg 1991;161: 90-5.

22. Thaha MA, Irvine LA, Steele RJ, Campbell KL. Postdefaecation pain syndrome after circular stapled anopexy is abolished by oral nifedipine. Br J Surg 2005;92:208-10.

23. George BD, Shetty D, Lindsey I, Mortensen NJ, Warren BF. Histopathology of stapled haemorrhoidectomy specimens: a cautionary note. Colorectal Dis 2002;4:473-6.

24. Altomare DF, Rinaldi M, Sallustio PL, Martino P, De Fazio M, Memeo V. Long-term effects of stapled haemorrhoidectomy on internal anal function and sensitivity. Br J Surg 2001;88:1487-91.

25. Corsetti M, De Nardi P, Di Pietro S, Passaretti S, Testoni PA, Staudacher C. Rectal distensibility and symptoms after stapled and Milligan-Morgan operation for hemorrhoids. J Gastrointest Surg 2009;13:2245-51. 